\title{
Repairing polycrystalline Inconel 100 using additive manufacturing
}

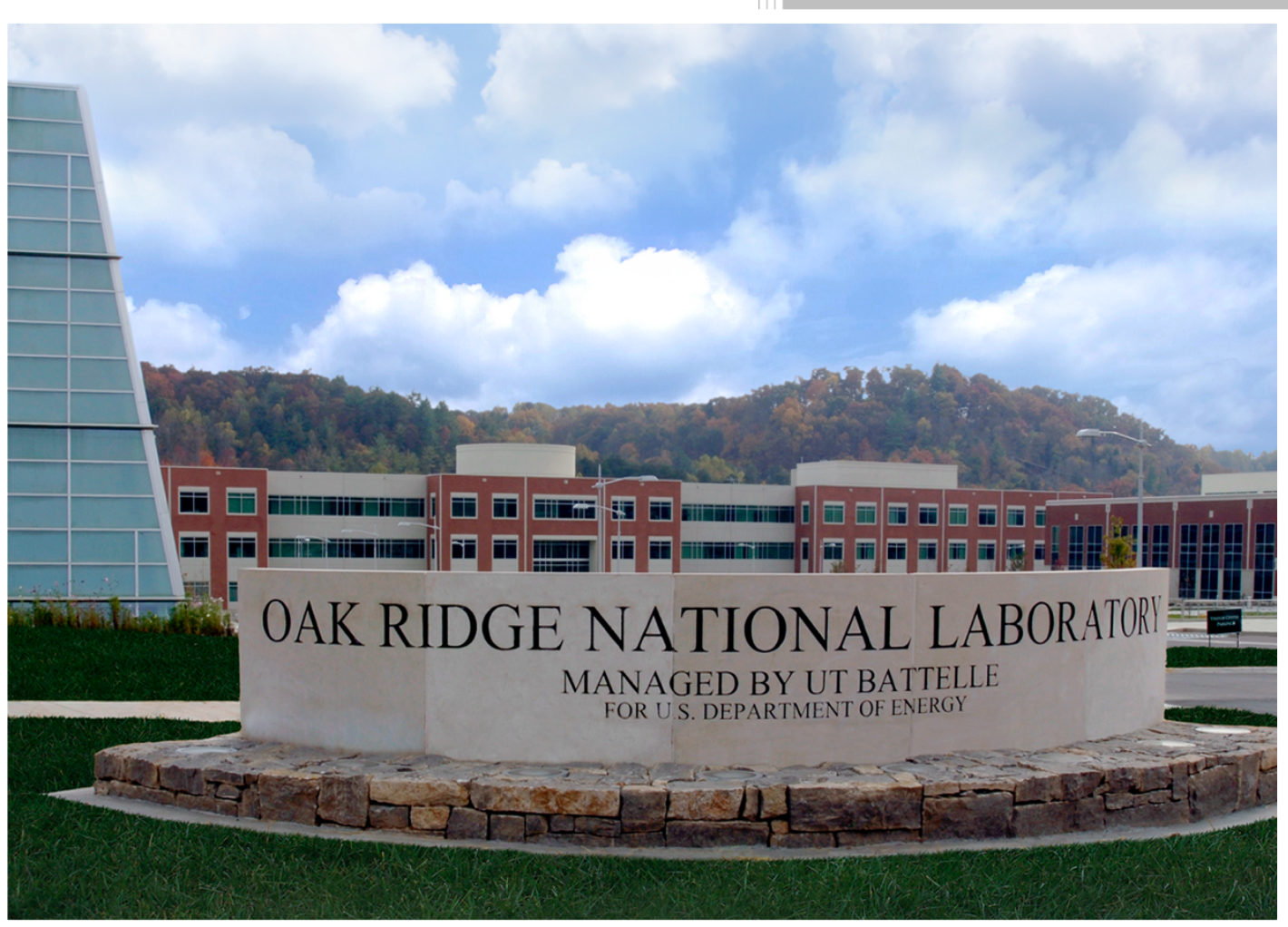

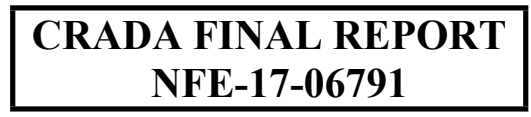

Approved for Public Release. Distribution is Unlimited.
Niyanth Sridharan

Yousub Lee

Brian H Jordan

Ramesh Ramakrishnan John Robertson Ryan Dehoff

January 8, 2019 


\section{DOCUMENT AVAILABILITY}

Reports produced after January 1, 1996, are generally available free via US Department of Energy (DOE) SciTech Connect.

Website http://www.osti.gov/scitech/

Reports produced before January 1, 1996, may be purchased by members of the public from the following source:

National Technical Information Service

5285 Port Royal Road

Springfield, VA 22161

Telephone 703-605-6000 (1-800-553-6847)

TDD 703-487-4639

Fax 703-605-6900

E-mail info@ntis.gov

Website http://www.ntis.gov/help/ordermethods.aspx

Reports are available to DOE employees, DOE contractors, Energy Technology Data Exchange representatives, and International Nuclear Information System representatives from the following source:

Office of Scientific and Technical Information

PO Box 62

Oak Ridge, TN 37831

Telephone 865-576-8401

Fax 865-576-5728

E-mail reports@osti.gov

Website http://www.osti.gov/contact.html

This report was prepared as an account of work sponsored by an agency of the United States Government. Neither the United States Government nor any agency thereof, nor any of their employees, makes any warranty, express or implied, or assumes any legal liability or responsibility for the accuracy, completeness, or usefulness of any information, apparatus, product, or process disclosed, or represents that its use would not infringe privately owned rights. Reference herein to any specific commercial product, process, or service by trade name, trademark, manufacturer, or otherwise, does not necessarily constitute or imply its endorsement, recommendation, or favoring by the United States Government or any agency thereof. The views and opinions of authors expressed herein do not necessarily state or reflect those of the United States Government or any agency thereof. 
ORNL/TM-2019/1071

CRADA/NFE-17-06791

Advanced Manufacturing Office

Materials Science and Technology Division

\title{
REPAIRING POLYCRYSTALLINE IN 100 USING LASER BLOWN POWDER ADDITIVE MANUFACTURING
}

\author{
Author(s) \\ Niyanth Sridharan \\ Yousub Lee \\ Brian H Jordan \\ Ramesh Ramakrishnan \\ John Robertson \\ Ryan Dehoff
}

Date Published:

January 8, 2019

Prepared by

OAK RIDGE NATIONAL LABORATORY

Oak Ridge, Tennessee 37831-6283

managed by

UT-BATTELLE, LLC

for the

US DEPARTMENT OF ENERGY

under contract DE-AC05-00OR22725

Approved For Public Release 



\section{CONTENTS}

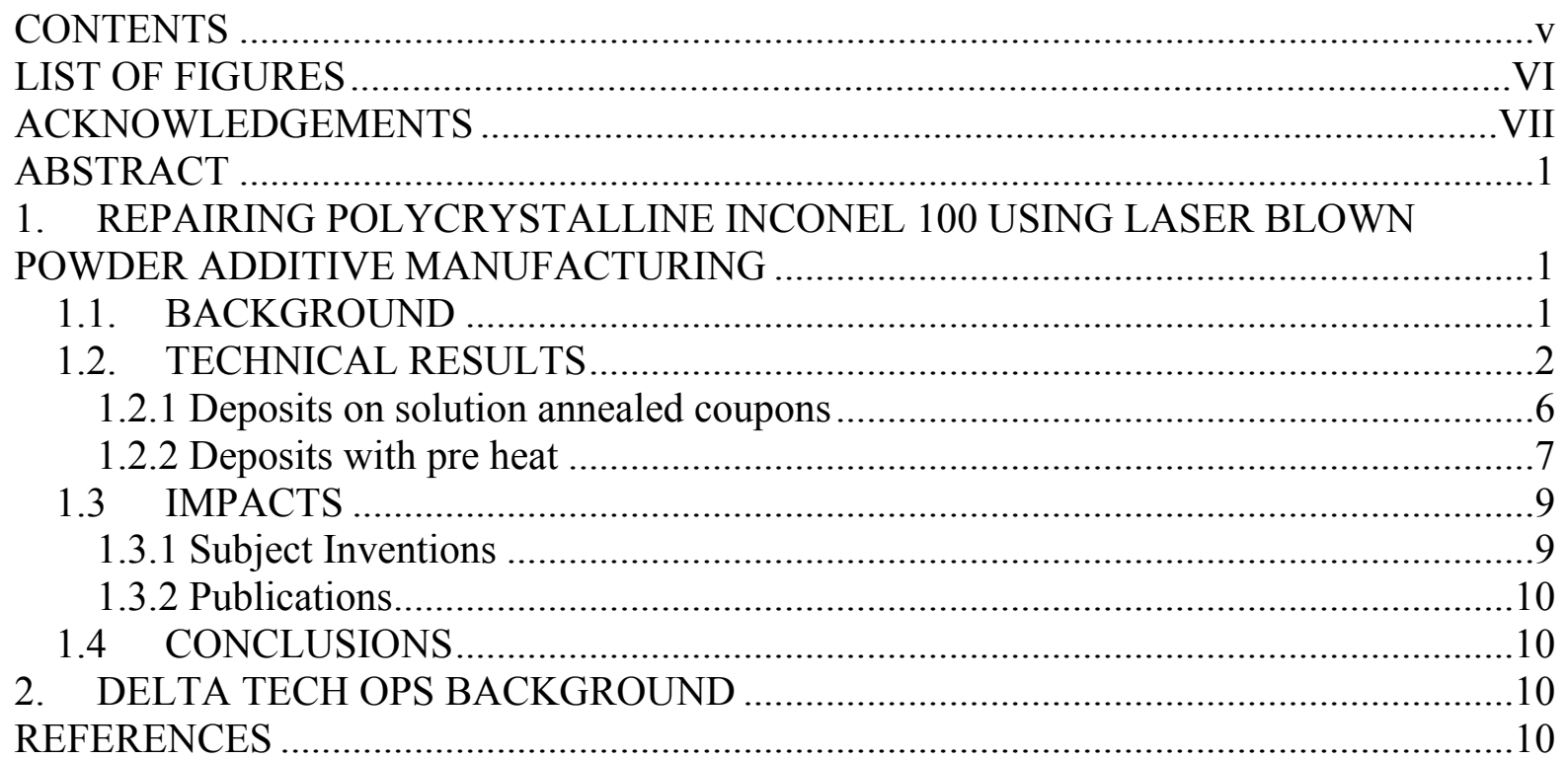


Toc525145479

\section{LIST OF FIGURES}

Figure 1: Microstructure of the (a)-(c) in the as received condition showing the presence of $\gamma^{\prime}$ and $\mathrm{Hf} / \mathrm{Ta}$ rich grain boundary carbides (d)-(f) in the solution annealed condition showing that the treatment dissolved the grain boundary carbides and also modified the $\gamma^{\prime}$ morphology.....

Figure 2: Micrographs of the coupons on which the deposits were fabricated. The arrow indicates the direction of laser travel where the head points towards the end of the build. Samples (a)-(f) correspond to samples fabricated using trial-1 thru' 6 . Note that the samples fabricated with a tighter hatch spacing and lower speeds reduced the cracking tendency.........4 Figure 3: Micrographs showing the cracking at the heat affected zone and the substrate. (a)(f) corresponding to the various trials

Figure 4: Micrographs (a)-(c) showing the presence of cracking in the beginning of the deposit only at the start of the build (d)-(f) showing the presence of cracking at the heat affected zone at the end of the deposit. Note that this section does not have any cracks in the deposits.

Figure 5: Micrographs showing the cracking at the heat affected zone and in the substrate (a) Secondary electron image at low magnification showing the presence of liquid films indicating some form of hot cracking (b)-(c) higher magnification BSE micrographs showing melting of carbides near the crack. EDS showing the presence of $\mathrm{Hf} / \mathrm{Ta}$ rich carbides liquation.

Figure 6: Deposits fabricated in solution annealed plates. The while the total number of micro cracks are reduced the samples did show cracking in the heat affected zone of the substrate as shown in the micrographs (a)-(f)...

Figure 7: SEM micrographs of the cracked section. The cracks clearly show the presence of liquid film in the deposit shown at a higher magnification in (b) and in the substrate at a higher magnification (c). Even in the solution annealed substrates cracking occurred beside carbides suggesting liquation cracking....

Figure 8: Thermal (d) \&(d) and mechanical (a)\&(c) simulations of deposits fabricated at room temperature (a)\&(c) and of deposits fabricated with a pre heat of $650^{\circ} \mathrm{C}(\mathrm{c}) \&(\mathrm{~d})$ showing the influence of pre heating on the stresses on cooling. 8

Figure 9: Micrographs showing the absence of liquation cracking and solidification cracking in the deposits fabricated with a preheat of $750^{\circ} \mathrm{C}$. Note the absence of cracks despite the continuous network of grain boundary carbides in the heat affected zone. 


\section{ACKNOWLEDGEMENTS}

This (CRADA) No. NFE-17-06791 was conducted as a Technical Collaboration project within the Oak Ridge National Laboratory (ORNL) Manufacturing Demonstration Facility (MDF) sponsored by the US Department of Energy Advanced Manufacturing Office (CPS Agreement Number 24761). Opportunities for MDF technical collaborations are listed in the announcement "Manufacturing Demonstration Facility Technology Collaborations for US Manufacturers in Advanced Manufacturing and Materials Technologies" posted at http://web.ornl.gov/sci/manufacturing/docs/FBO-ORNL-MDF-2013-2.pdf. The goal of technical collaborations is to engage industry partners to participate in short-term, collaborative projects within the Manufacturing Demonstration Facility (MDF) to assess applicability and of new energy efficient manufacturing technologies. Research sponsored by the U.S. Department of Energy, Office of Energy Efficiency and Renewable Energy, Advanced Manufacturing Office, under contract DE-AC05-00OR22725 with UT-Battelle, LLC. 


\begin{abstract}
The overall goal of this Manufacturing Demonstration Facility (MDF) technical collaboration project is to extend the use of the laser blown powder additive manufacturing process to enable the repair of polycrystalline high $\gamma^{\prime} \mathrm{Ni}$ base super alloys, and to qualify the repaired parts for end use. The goal of phase 1 of this project was to evaluate the cracking susceptibility of Inconel 100 samples, and to identify parameters that would yield crack free repair deposits on representative geometries using a surrogate material as a substrate. A detailed design of experiments was performed in conjunction with thermomechanical modeling to determine processing conditions. A set of process parameters were identified which yielded minimal cracking. Further modeling was used to identify the preheat condition necessary to obtain crack free deposits. Following identification of the preheat, a furnace was integrated within the chamber of the blown powder Direct Energy Deposition (DED) system, and deposits were fabricated with on a preheated furnace. The results show that crack free deposits with dimensions $35 \times 15 \times 0.5 \mathrm{~mm}^{3}$ can be fabricated. With this success obtained in phase 1 the goal of phase 2, if awarded, would be to fabricate the deposit on the actual IN 100 substrates develop heat treatment procedures and qualify the repair procedures.
\end{abstract}

\title{
1. REPAIRING POLYCRYSTALLINE INCONEL 100 USING LASER BLOWN POWDER ADDITIVE MANUFACTURING
}

This phase 1 technical collaboration project MDF-TC-2017-121 was begun on July 19, 2017 and was completed on September 14, 2018. The collaboration partner Delta Tech Ops (DTO), a division of Delta Airlines Inc., is a large business. The results show that by proper control of the thermal profile of the builds crack free Inconel 100 deposits can be fabricated on representative coupons made using surrogate materials.

\subsection{BACKGROUND}

Nickel based super alloys are used in harsh operating conditions requiring high tensile strength, high creep strength and oxidation resistance [1]. To achieve through life cost reduction targets, component refurbishment, overhaul and repair are prime considerations for both Original Equipment Manufacturers (OEM) and operators[1][2]. However polycrystalline high $\gamma^{\prime} \mathrm{Ni}$ base super alloys also have poor weldability and are deemed "non weldable"[1][3]. Weldability in this context is defined as "the capacity of a material to be joined under the imposed fabrication conditions into a specific, suitably defined structure and to perform satisfactorily in the intended service with minimum defects and distortion"'[4][5]. The reason for the poor weldability is a myriad of cracking mechanisms such as solidification cracking, strain age cracking and liquation cracking which operate simultaneously [1].

Solidification cracking occurs within the solidified deposit when the mushy zone experiences tensile stresses and high fraction of solid (typically $\mathrm{f}_{\mathrm{s}}>0.9$ ) restricts the flow of liquid metal to backfill the interdendritic regions. The thermal stresses then lead to tearing along the grain boundaries[1][4].

Grain boundary liquation occurs primarily due to the localized dissolution of the precipitates 
and grain boundary phases such as carbides [4][6]. Under rapid heating to above the solvus temperatures of the precipitates, the precipitates are unable to dissolve completely which leads to the formation of low melting eutectic phases [6]. A liquid film forms which embrittles the grain boundaries leading to tearing under the tensile thermal stresses which develop during the welding.

Strain age cracking on the other hand occurs during the post weld heat treatment stage. These defects are characterized by intergranular micro-cracking as a result of precipitation hardening of the alloy which then transfers the solidification stresses onto the grain boundaries. The classical way to avoid this problem is either to solutionize the material or overage the material before welding. This approach combined with using a more ductile filler material such as IN-625, and by a careful design of post processing heat treatments, has shown to be an effective way to mitigate this cracking mechanism. In many cases all these mechanisms operate simultaneously [6].

In the past, some traditional repair techniques such as plasma spraying, plasma transfer arc welding, tungsten inert gas welding have been adopted. While these have limited successes, these techniques often suffer from large mushy zone formation which leads to cracking in the welded layers. High heat input repair welding often leads to the heat affected zone liquation cracking and hot cracking in the fusion zone [1], [2], [7]. Hence it is important to develop localized repair processes.

Recently laser metal deposition techniques have been used to repair weld materials. The laser beam melts a thin layer of the substrate (part to be repaired) and powder is injected into the melt pool resulting in a metallurgically bonded deposit. Despite these benefits it is challenging to deposit the high strength Ni based super alloys due to their high $\gamma$ ' content. A $\mathrm{Ni}$ based alloy is considered difficult to weld when the Al+Ti content exceeds $4 \mathrm{wt} \%$. Polycrystalline Inconel (IN) 100 which contains more than $50 \mathrm{vol} \%$ of $\gamma^{\prime}$ is one of the most difficult to weld Ni base super alloys [3]. To overcome this most of the repairs done today entail depositing a ductile filler material (such as IN-625) in the low stress region of the part[1], [2]. Rarely have attempts been performed to repair these structures with a matching filler material. The present investigation demonstrates single layer repair of IN 100 with $35 \times 15 \mathrm{~mm}^{3}$ and $0.5 \mathrm{~mm}$ thick layer deposited on surrogate substrate with representative geometries due to the difficulties in procuring the actual material as a substrate.

\subsection{TECHNICAL RESULTS}

The laser directed energy deposition process utilizes a laser focused on a substrate material creating a melt pool into which powder is "sprayed" co-axially or via an off axis technique to deposit material. The laser head then rasters in the $\mathrm{X}-\mathrm{Y}$ plane at a programmed velocity and the entire assembly moves up in $\mathrm{Z}$ direction once the layer is complete. The DM3D 103D system located at the ORNL Manufacturing Demonstration Facility (MDF)is equipped with a $1 \mathrm{~kW}$ diode laser with a wavelength of $910 \mathrm{~nm}$. The laser spot size is $1.5 \mathrm{~mm}$. The stand off distance between the substrate and the laser head is $\sim 12 \mathrm{~mm}$. The builds in this project were fabricated with Ar shielding (99/9\% pure) with a flow rate of $6 \mathrm{lpm}$. The composition of the substrate material used is shown in table 1, and the powder material used was IN 100 . The IN 100 powder was gas atomized with a size distribution of 40-120 $\mu \mathrm{m}$ diameter. The hall flow rate of the powder was $19 \mathrm{~s}$. The compositions of the substrate and powder alloys are presented in table 1. 
Table 1: Composition of the substrate and powder used in this study

\begin{tabular}{|l|c|c|c|c|c|c|c|c|c|c|}
\hline Alloy & $\begin{array}{l}\mathrm{W} \\
\mathrm{wt} \%\end{array}$ & $\begin{array}{l}\mathrm{Co} \\
\mathrm{wt} \%\end{array}$ & $\begin{array}{l}\mathrm{Cr} \\
\mathrm{wt} \%\end{array}$ & $\begin{array}{l}\mathrm{Al} \\
\mathrm{wt} \%\end{array}$ & $\begin{array}{l}\mathrm{Ta} \\
\mathrm{wt} \%\end{array}$ & $\begin{array}{l}\mathrm{Hf} \\
\mathrm{wt} \%\end{array}$ & $\begin{array}{l}\mathrm{Ti} \\
\mathrm{wt} \%\end{array}$ & $\begin{array}{l}\mathrm{Mo} \\
\mathrm{wt} \%\end{array}$ & $\begin{array}{l}\mathrm{C} \\
\mathrm{wt} \%\end{array}$ & $\begin{array}{l}\mathrm{Ni} \\
\mathrm{wt} \%\end{array}$ \\
\hline Substrate & 10.19 & 9.92 & 8.40 & 5.58 & 3.12 & 1.11 & 0.92 & 0.64 & 0.13 & $\mathrm{Bal}$ \\
\hline IN 100 & - & 18.4 & 12.4 & 4.9 & - & - & 4.3 & 3.2 & 0.07 & Bal \\
\hline
\end{tabular}

The substrate was characterized using optical microscopy and scanning electron microscopy. Samples were mounted and polished using regular metallographic methods and etched using Kallings reagent to reveal the microstructure. Results are shown in figure 1. Figure 1 (a)-(c) show the optical and SEM micrographs of the substrate samples in the as received conditions. The microstructure clearly shows a bi modal distribution of $\gamma^{\prime}$ with $\mathrm{Hf} / \mathrm{Ta}$ rich carbides along the grain boundaries. Such continuous network of carbides acts as potential sites for liquation cracking during repair. Therefore to eliminate the carbides and coarsen the $\gamma^{\prime}$ a subsolvus solution annealing treatment was given to the substrates. The as received coupons were solution annealed at $1093^{\circ} \mathrm{C}$ for 2 hours in a vacuum furnace. The solution annealing treatment was a sub solvus treatment. The solution annealed substrates are also shown in figure 1(d)-(f). Solution annealing led to the dissolution of the continuous network of carbides along the grain boundary. While the grain boundary carbides dissolved, energydispersive spectroscopy (EDS) showed that the actual composition of the carbides did not change. In addition the procedure coarsened the secondary $\gamma^{\prime}$ precipitates, and caused the dissolution of the continuous network of grain boundary carbides.
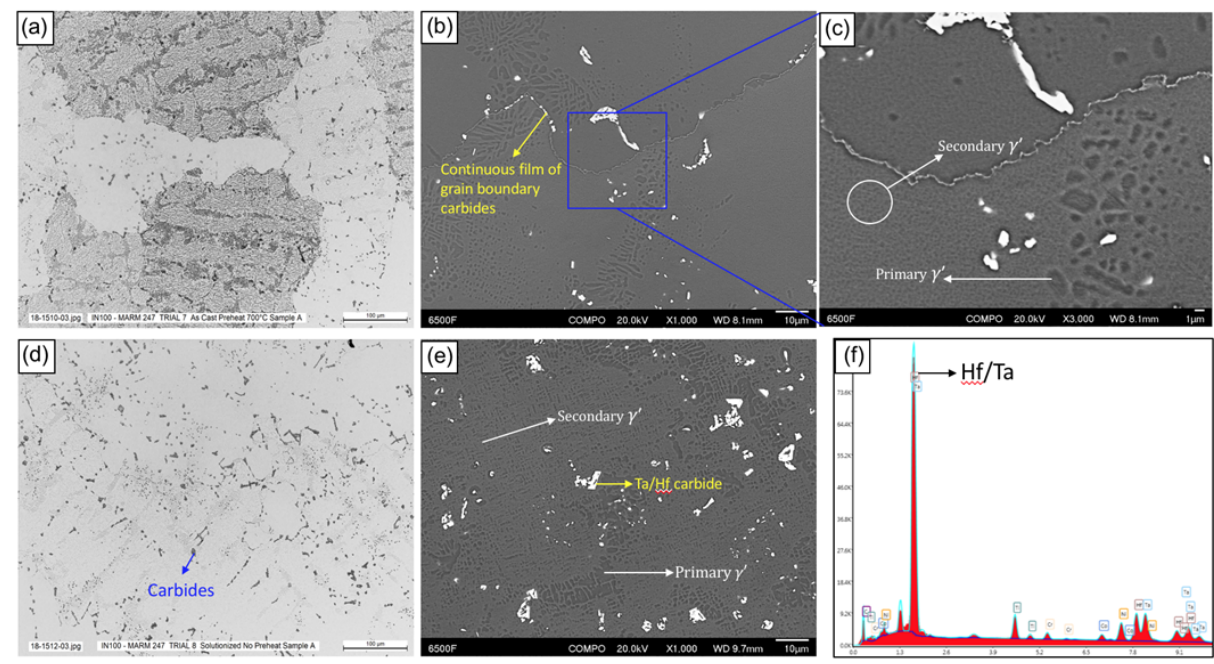

Figure 1: Microstructure of the substrate (a)-(c) in the as received condition showing the presence of $\boldsymbol{\gamma}^{\prime}$ and $\mathrm{Hf} /$ Ta rich grain boundary carbides (d)-(f) in the solution annealed condition showing that the treatment dissolved the grain boundary carbides and also modified the $\boldsymbol{\gamma}^{\prime}$ morphology

One of the most critical parameters used to control the cracking susceptibility of the deposit is heat input. In terms of the process parameters laser power, travel speed, powder feed rate, hatch spacing and preheat can be modified. In general terms, welding with lower heat input leads to reduction in liquation cracking in the substrate material [1], [7], [8]. To identify the range of processing parameters, a detailed design of experiments (DOE) approach was used to understand the optimum range of process parameters to eliminate cracking. The DOE table used is presented in table 2 . The energy density calculated using the following relation 


$$
\text { Energy Density }=\frac{\text { Power }}{(\text { Velocity } \times \text { hatch } \times \text { layer thickness })}
$$

Table 2 Process parameters used to evaluate cracking susceptibility in the builds

\begin{tabular}{|c|c|c|c|c|c|}
\hline & $\begin{array}{c}\text { Laser } \\
\text { power } \\
(\mathrm{W})\end{array}$ & $\begin{array}{c}\text { Travel } \\
\text { speed } \\
(\mathrm{mm} / \mathrm{min})\end{array}$ & $\begin{array}{c}\text { Hatch } \\
\text { Spacing } \\
(\mathrm{mm})\end{array}$ & $\begin{array}{c}\text { Powder feed } \\
\text { rate } \\
(\mathrm{gram} / \text { minute })\end{array}$ & $\begin{array}{c}\text { Energy } \\
\text { Density } \\
\left(\mathrm{J} / \mathrm{mm}^{3}\right)\end{array}$ \\
\hline Trial 1 & 400 & 800 & 0.6 & 4 & 100 \\
\hline Trial 2 & 400 & 1000 & 0.6 & 4 & 80 \\
\hline Trial 3 & 400 & 800 & 0.5 & 4 & 120 \\
\hline Trial 4 & 600 & 800 & 0.6 & 4 & 150 \\
\hline Trial 5 & 600 & 1000 & 0.6 & 4 & 120 \\
\hline Trial 6 & 600 & 1000 & 0.5 & 4 & 144 \\
\hline
\end{tabular}

The results of the deposition trials are shown in figure 2. Figure 2 shows that the best results were obtained for deposits fabricated using a tighter hatch spacing. In addition, figure 3 shows the deposit substrate interface at higher magnification. The micrographs clearly shows that most of the cracking occurred at the heat affected zone. The cracks then propagated to the deposited material.
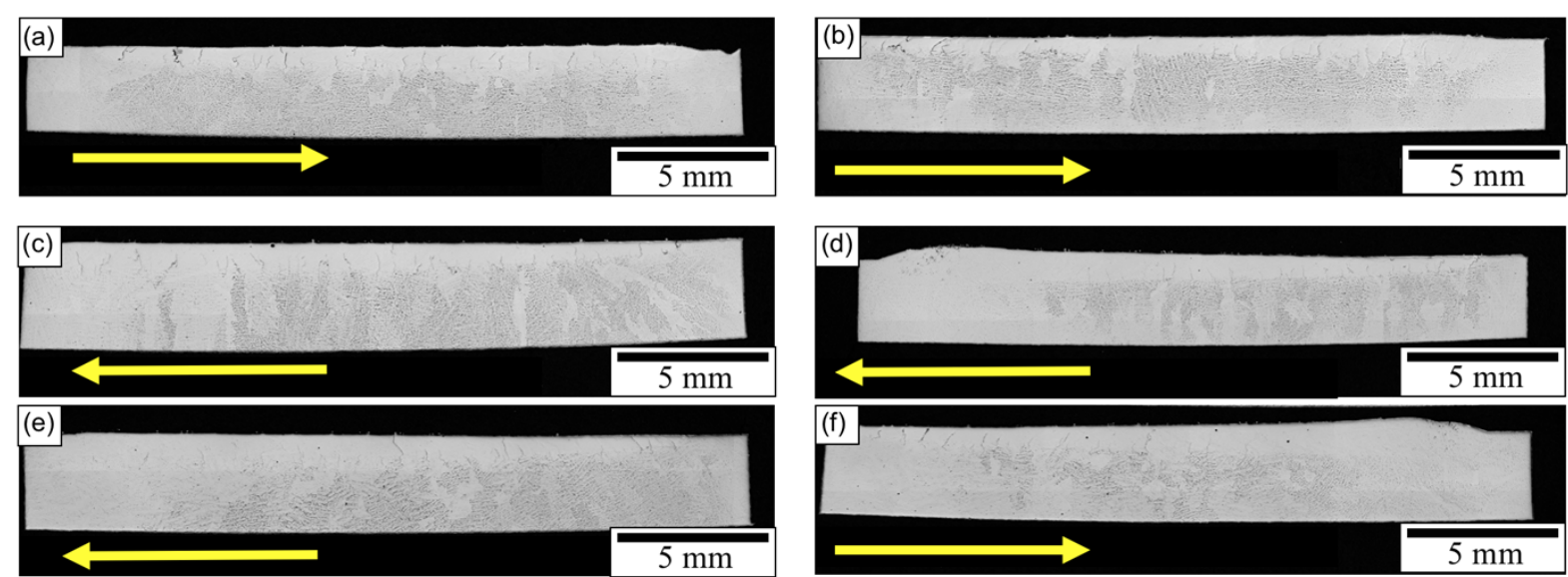

Figure 2: Micrographs of the coupons on which the deposits were fabricated. The arrow indicates the direction of laser travel where the head points towards the end of the build. Samples (a)-(f) correspond to samples fabricated using trial-1 thru' 6 . Note that the samples fabricated with a tighter hatch spacing and lower speeds reduced the cracking tendency. 

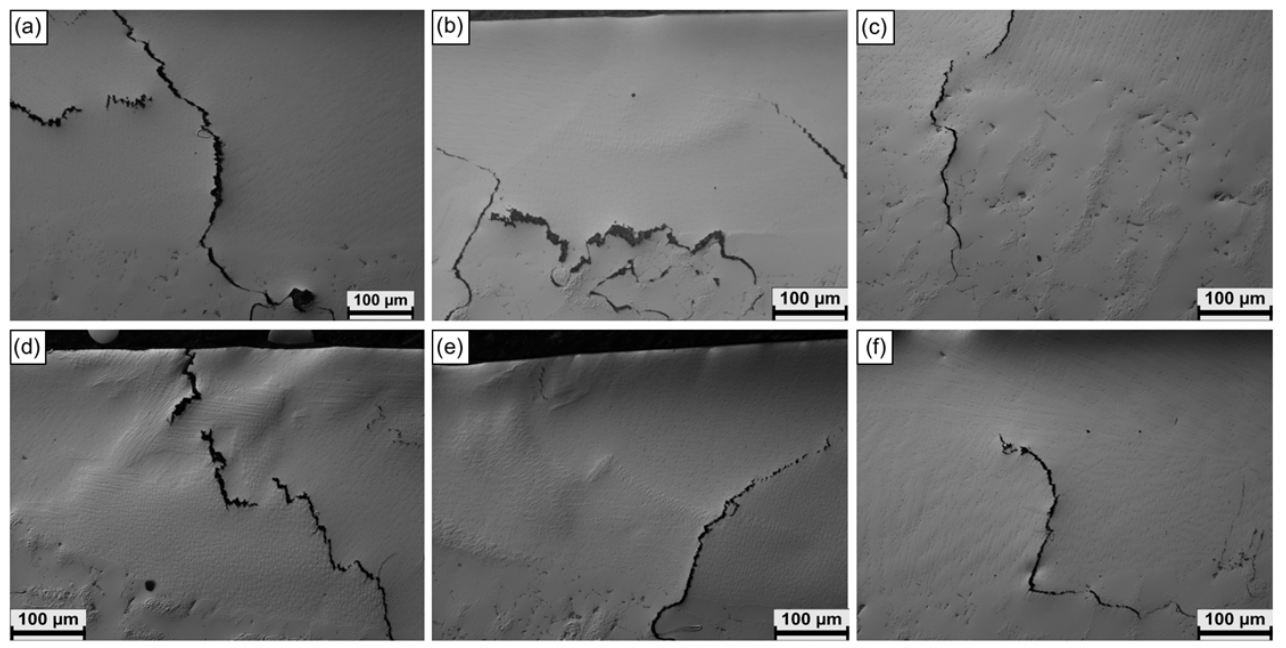

Figure 3: Micrographs showing the cracking at the heat affected zone and the substrate. (a)-(f) corresponding to the various trials

Based on these results the parameters with a laser power of $600 \mathrm{~W}, 1000 \mathrm{~mm} / \mathrm{min}$ and a hatch spacing of $0.5 \mathrm{~mm}$ showed minimum cracking. This seems to be counter intuitive since the energy density of the samples corresponding to parameter set 2 has the lowest energy density and therefore should be least susceptible to cracking. Since the post characterization examination clearly showed that parameters corresponding to trail 6 showed the least amount of cracking this was identified to be ideal process parameters to eliminate cracking. A tighter hatch spacing while leading to a reduction in cracking during deposition leads to overbuilding of the deposit. The cracking tendency is reduced in this case probably due to a reduction in the thermal stresses associated with a shallower thermal gradient in the builds. Therefore the powder feed rate needs to be optimized accounting for this increase in powder capture efficiency. However for this study the trail 6 was selected for a more detailed characterization study to investigate the mechanisms of cracking. Cracking mechanisms need to be identified so that effective strategies can be designed to mitigate them. However, this is by no means an exhaustive DOE study, and a more detailed DOE study to incorporate scan strategies and wider range of pre heats is needed. This more detailed work will be performed in phase 2 .
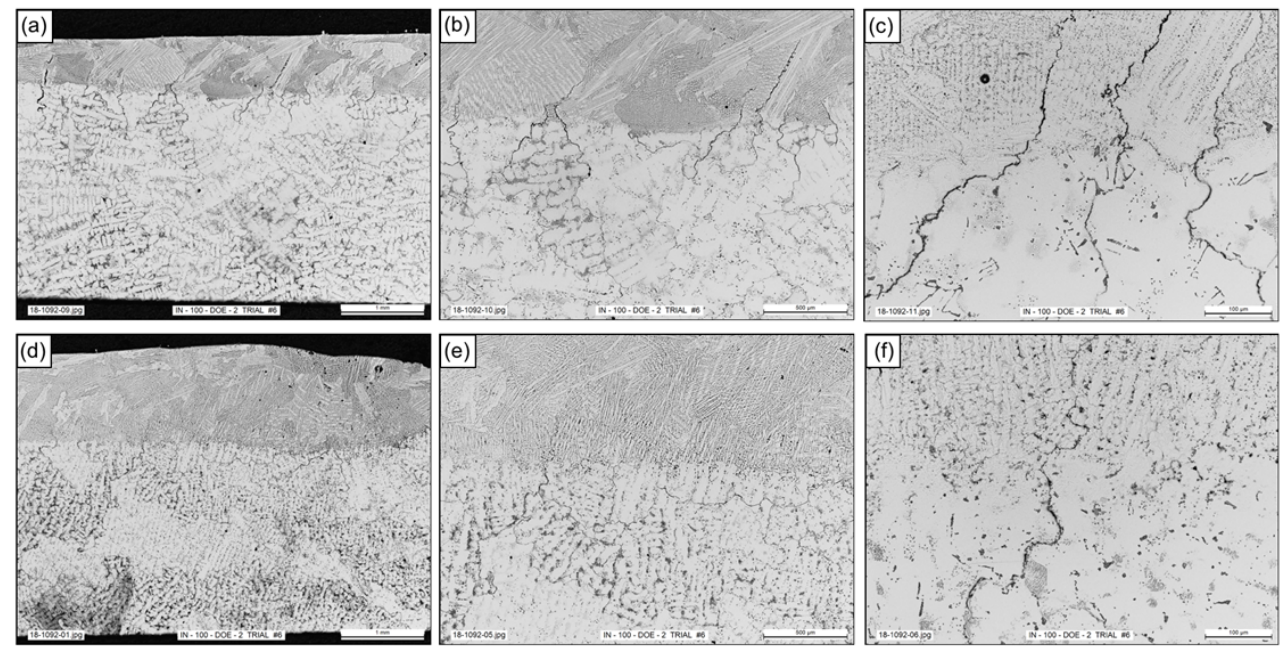
Figure 4: Micrographs (a)-(c) showing the presence of cracking in the beginning of the deposit only at the start of the build (d)-(f) showing the presence of cracking at the heat affected zone at the end of the deposit. Note that this section does not have any cracks in the deposits.
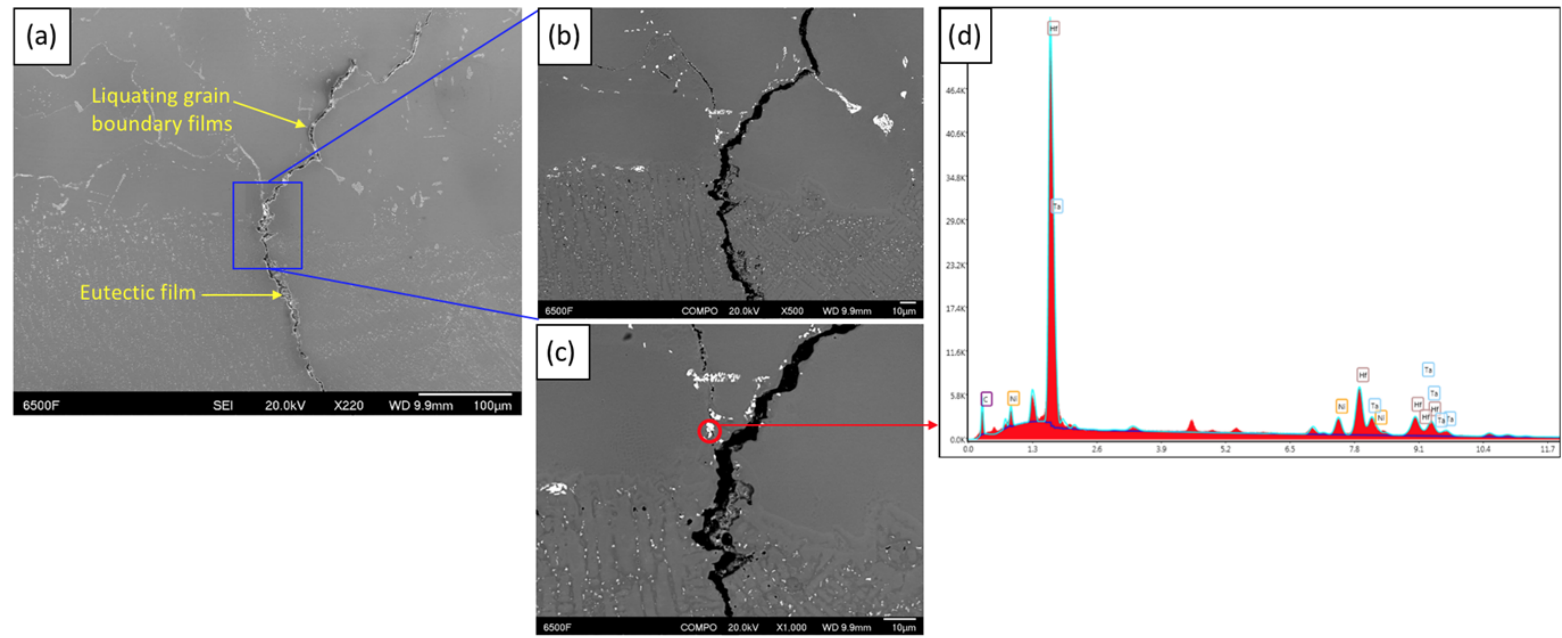

Figure 5: Micrographs showing the cracking at the heat affected zone and in the substrate (a) Secondary electron image at low magnification showing the presence of liquid films indicating some form of hot cracking (b)-(c) higher magnification Back Scatter Electron (BSE) micrographs showing melting of carbides near the crack. EDS showing the presence of Hf/Ta rich carbides liquation.

Figures 4 and 5 show the interface structure of the deposits fabricated on the as cast substrate. The optical micrograph clearly shows that the cracking predominantly occurs in the heat affected zone. This mechanism of cracking could be attributed to heat affected zone liquation cracking. To conduct a more detailed investigation of the cracking mechanism detailed Scanning Electron Microscopy (SEM) microscopy was performed. The SEM microscopy clearly shows the presence of liquid films along the carbides. This mechanism is well known and has been documented in the existing literature [7]. The carbides were identified to be rich in $\mathrm{Hf}$ and $\mathrm{Ti}$, as shown in the EDS spot analysis. Note that the cracks initiate in the heat affected zone and propagate into the deposit. However the cracking in the deposit is attributed to solidification cracking, which is evident from the formation of eutectic films at the interface [4], [5]. In addition to this characterization of the as deposited structure shows the presence of carbides in the interdendritic region due to the $\mathrm{L} \rightarrow \mathrm{MC}(\mathrm{Hf} / \mathrm{Ta})+\gamma$ eutectic reaction during the solidification. However, no evidence was observed for the constitutive liquation in the deposit. Nearly all the cracks in the deposit were solidification cracks.

\subsubsection{Deposits on solution annealed coupons}

Previous reports have shown that solution annealing the substrates before repairing resulted in improved resistance to cracking. Figure 1 clearly shows that solution annealing plates eliminated the continuous grain boundary carbides and also coarsened the fine secondary $\gamma^{\prime}$ precipitates in the as received material. The post deposit optical micrographs are shown in figure 6 . 


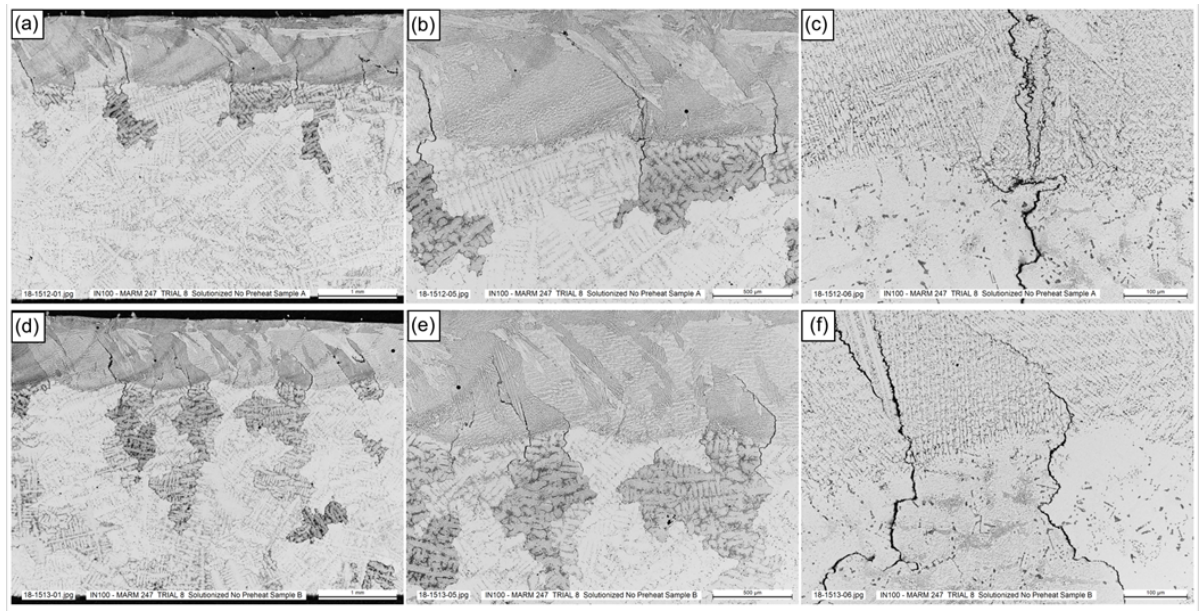

Figure 6: Deposits fabricated in solution annealed plates. The while the total number of micro cracks are reduced the samples did show cracking in the heat affected zone of the substrate as shown in the micrographs (a)-(f)
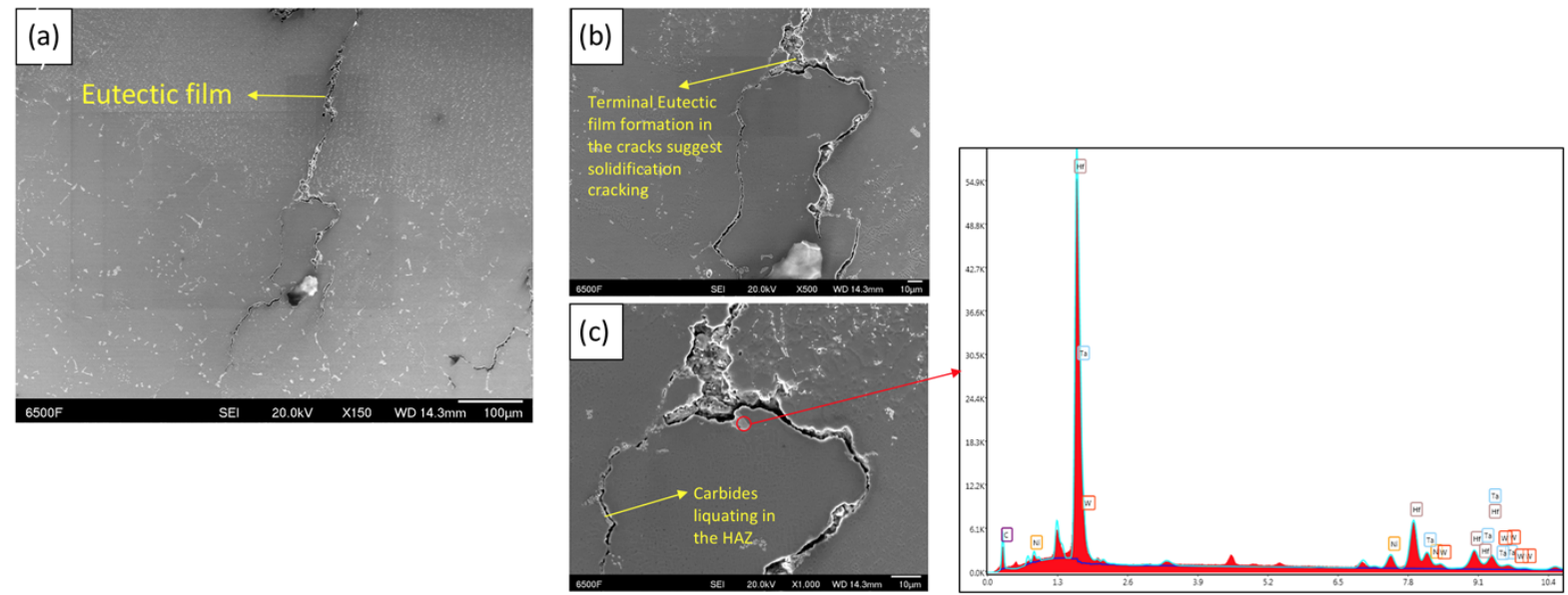

Figure 7: SEM micrographs of the cracked section. The cracks clearly show the presence of liquid film in the deposit shown at a higher magnification in (b) and in the substrate at a higher magnification (c). Even in the solution annealed substrates cracking occurred beside carbides suggesting liquation cracking

The deposits indicate that the cracking tendency is lower in the solutionized samples in comparison to the as received samples. This can be attributed to the elimination of grain boundary carbides and coarsening of $\gamma^{\prime}$ eutectic as a result of the solution annealing treatment. Detailed SEM investigations were performed to identify the cracking mechanisms. The micrographs are shown in figure 7 (a)-(c). The SEM micrographs show that similar cracking mechanisms operate despite the solution annealing treatments being performed. The heat affected zone cracking persists and occurs adjacent to the carbide phases which liquate as shown in figure 7(c). In this case as well the cracks in the IN 100 deposits were predominantly attributed to solidification cracking as shown in figure 7(b). While solution annealing reduced the cracking susceptibility in the builds, it was not possible for solution annealing to completely eliminate cracking in the deposits. 


\subsubsection{Deposits with pre heat}

Solidification and liquation cracking in Ni base super alloys, which is the dominant cracking mechanism in this case has been attributed to

i. Presence of a liquid film

ii. Shrinkage stresses arising from thermal strains[4], [5].

It has been reported that preheating the substrate leads to a reduction in the cracking tendency primarily by relieving the strains [9]. Therefore to identify the ideal pre heat temperature where the net tensile strain in the build during solidification is low, modeling was performed. The results are presented below in figure 8 .

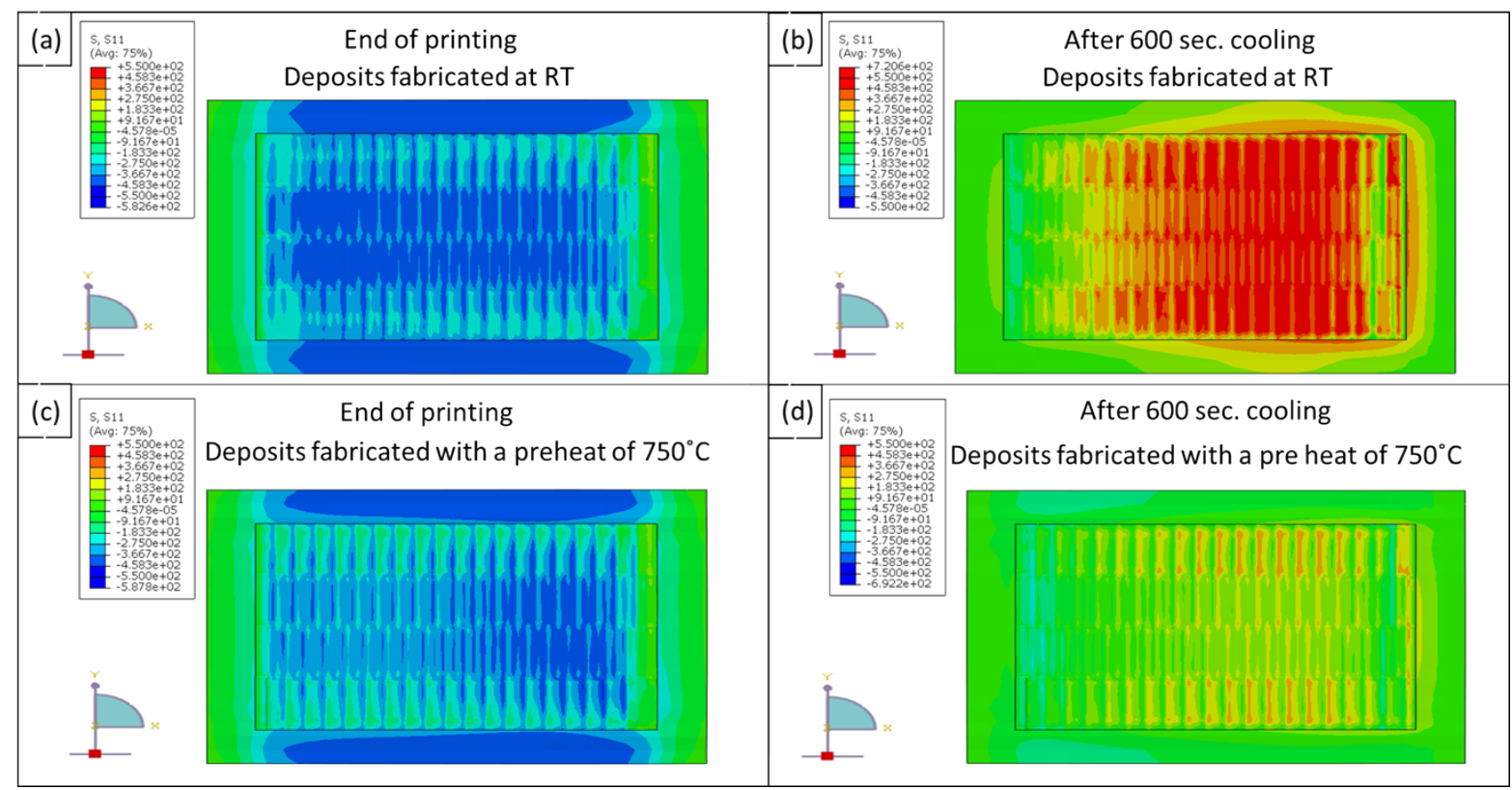

Figure 8: Thermal-mechanical simulations of deposits fabricated at room temperature (a) \& (b) and of deposits fabricated with a pre heat of $750^{\circ} \mathrm{C}$ (c) \& (d). The stress comparison of RT (b) to preheat (d) show that $750^{\circ} \mathrm{C}$ preheat on the deposit significantly reduces the residual stress arising during cooling.

Figure 8(a) and (b) shows the stress development in the deposit when fabricated on coupons at room temperature. Note the significant tensile residual stress in the deposit and the substrate in Fig.8(b). However, when the preheat on the substrate is increased to $750^{\circ} \mathrm{C}$, the deposit displays an overwhelmingly less residual stress during cooling in Fig.8(d). Therefore, preheating more than $750^{\circ} \mathrm{C}$ and cooling slowly may have led to mitigation or elimination of cracks. Based on these results attempts to fabricate deposits with a pre heat temperature of $750^{\circ} \mathrm{C}$ was made by integrating an industrial hot plate inside the build chamber of laser deposition machine. The micrographs of the pre-heated deposits are shown in figure 9. 

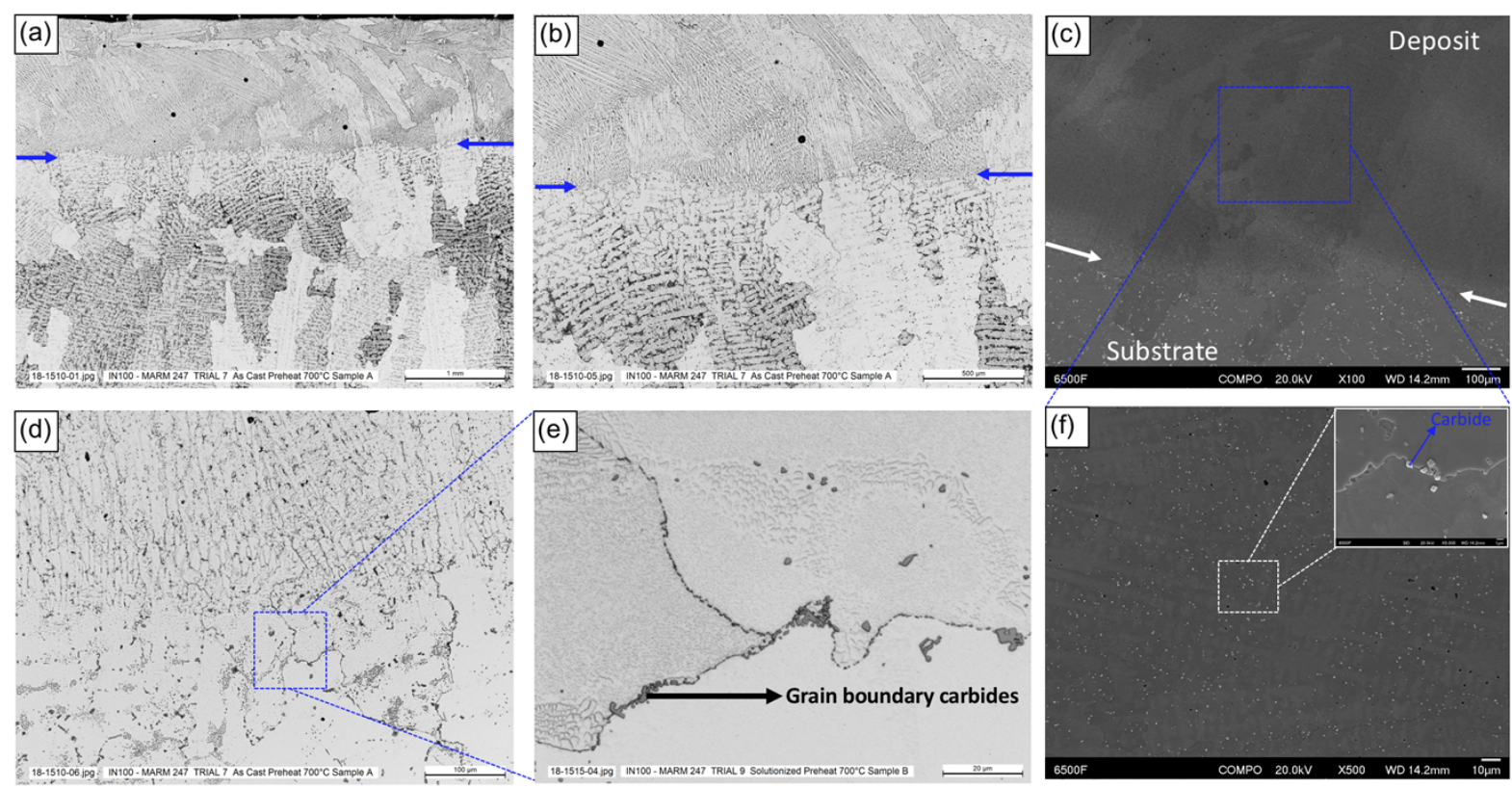

Figure 9: Micrographs showing the absence of liquation cracking and solidification cracking in the deposits fabricated with a preheat of $750^{\circ} \mathrm{C}$. Note the absence of cracks despite the continuous network of grain boundary carbides in the heat affected zone

Figures 9(a)\&(b) show the deposit substrate interface without any cracks. Figure 9(c)-(e) show the same interface at higher magnification showing that despite the presence of significant grain boundary carbide phases similar to the as received material, cracking did not occur. This would have been due to the shallower thermal gradients experienced by the material, which could have suppressed the liquation of these grain boundary carbide phases. Figure 9(f) shows the micrograph of the deposit. No $\gamma^{\prime}$ was observed in the deposit, however the inset shows the deposit at higher magnification showing the presence of carbides present in the interdendritic region. Based on the extent of characterization performed within phase 1 it is clear that the deposit fabricated by pre heating the substrate did not show any major difference with those fabricated without any preheat. However the role of strain age cracking during post weld heat treatment of the deposits were not evaluated. This will be performed in phase 2 of this work.

\subsection{IMPACTS}

The phase- 1 has provided a definite proof of principle that crack susceptible high $\gamma^{\prime}$ Ni base super alloys can be successfully repaired using this technology. While the phase- 1 has demonstrated the proof of principle the phase 2 is a much more focused effort aimed at extending the knowledge and processing parameters obtained via phase 1 to actually repair, post process and qualify the repaired part.

If phase 2 is approved, the project would help DTO adopt advanced manufacturing techniques to facilitate repair in their shops. For instance it has been shown that when the repair volume is $10 \%$ $(1.56 \mathrm{Kg})$ respective to the deposited material there is at least a $45 \%$ carbon footprint improvement and a 36\% savings in total energy over replacing with a new blade. In addition it has been reported that replacing conventional welding techniques with AM a further reduction of $15 \%$ in emissions can be achieved. 


\subsubsection{Subject Inventions}

There are no subject inventions associated with this CRADA .

\subsection{CONCLUSIONS}

Though not exhaustive, phase 1 demonstrates the proof of principle that IN 100 could be deposited by laser blown powder additive manufacturing without any cracking. The major factor leading to cracking in the builds is due to the presence of liquation films and shrinkage stresses. These were eliminated by utilizing a high preheat temperature which lead to the decrease in the total buildup of the stresses which resulted in a decreased susceptibility to cracking. Phase 2 of this project would focus on refining these processing conditions to ensure crack free IN 100 deposits can be deposited on on IN 100 substrates. Also, no post weld heat treatments were performed to identify susceptibility to strain age cracking. Therefore one the major efforts in phase 2 of this program would be to perform detailed post weld heat treatments to investigate the susceptibility of the deposit to strain age cracking. In addition phase 2 would develop a generic template to process other $\gamma^{\prime}$ and Ni base super alloys and develop post processing rejuvenation treatments for the same. Phase 2 would also seek to utilize in situ process monitoring to qualify the fabrication procedure.

\section{DELTA TECH OPS BACKGROUND}

Delta Air Lines is one of the world's largest commercial airline serving nearly 180 million customers each year. In 2016, Delta was named to Fortune's top 50 most admired Companies in addition to being named the most admired airline for the fifth time in six years.

Additionally, Delta has ranked No.1 in the Business Travel News Annual Airline survey for an unprecedented six consecutive years. With an industry-leading global network, Delta and the Delta Connection carriers offer service to 323 destinations in 57 countries on six continents. Headquartered in Atlanta, Delta employs more than 80,000 employees worldwide and operates a mainline fleet of more than 800 aircraft. Delta Tech Ops (DTO) is a division of Delta Air Lines. Over 9,600 Technical Operations employees system-wide provide fullservice aviation maintenance to Delta and service its fleet of more than 800 aircraft. In addition, DTO provides complete maintenance for more than 150 other operators.

\section{REFERENCES}

[1] M. B. Henderson, D. Arrell, R. Larsson, M. Heobel, and G. Marchant, "Nickel based superalloy welding practices for industrial gas turbine applications," Sci. Technol. Weld. Join., vol. 9, no. 1, pp. 13-21, 2004.

[2] L. Sexton, S. Lavin, G. Byrne, and A. Kennedy, "Laser cladding of aerospace materials," J. Mater. Process. Technol., 2002.

[3] R. Acharya and S. Das, "Additive manufacturing of IN100 superalloy through scanning laser epitaxy for turbine engine hot-section component repair: process development, modeling, microstructural characterization, and process control," Metall. Mater. Trans. A, vol. 46, no. 9, pp. 3864-3875, 2015. 
[4] S. A. David, J. A. Siefert, J. N. DuPont, and J. P. Shingledecker, "Weldability and weld performance of candidate nickel base superalloys for advanced ultrasupercritical fossil power plants part I: fundamentals," Sci. Technol. Weld. Join., vol. 20, no. 7, pp. 532-552, 2015.

[5] J. A. Siefert, J. P. Shingledecker, J. N. DuPont, and S. A. David, "Weldability and weld performance of candidate nickel based superalloys for advanced ultrasupercritical fossil power plants Part II: weldability and cross-weld creep performance," Sci. Technol. Weld. Join., vol. 21, no. 5, pp. 397-427, 2016.

[6] M. B. Henderson, D. Arrell, M. Heobel, R. Larsson, and G. Marchant, "Nickel-Based Superalloy Welding Practices for Industrial Gas Turbine Applications," Sci. Technol. Weld. Join., 2004.

[7] M. Zhong, H. Sun, W. Liu, X. Zhu, and J. He, "Boundary liquation and interface cracking characterization in laser deposition of Inconel 738 on directionally solidified Ni-based superalloy," Scr. Mater., 2005.

[8] A. T. Egbewande, R. A. Buckson, and O. A. Ojo, "Analysis of laser beam weldability of Inconel 738 superalloy," Mater. Charact., 2010.

[9] M. F. Chiang and C. Chen, "Induction-assisted laser welding of IN-738 nickel-base superalloy," Mater. Chem. Phys., 2009. 